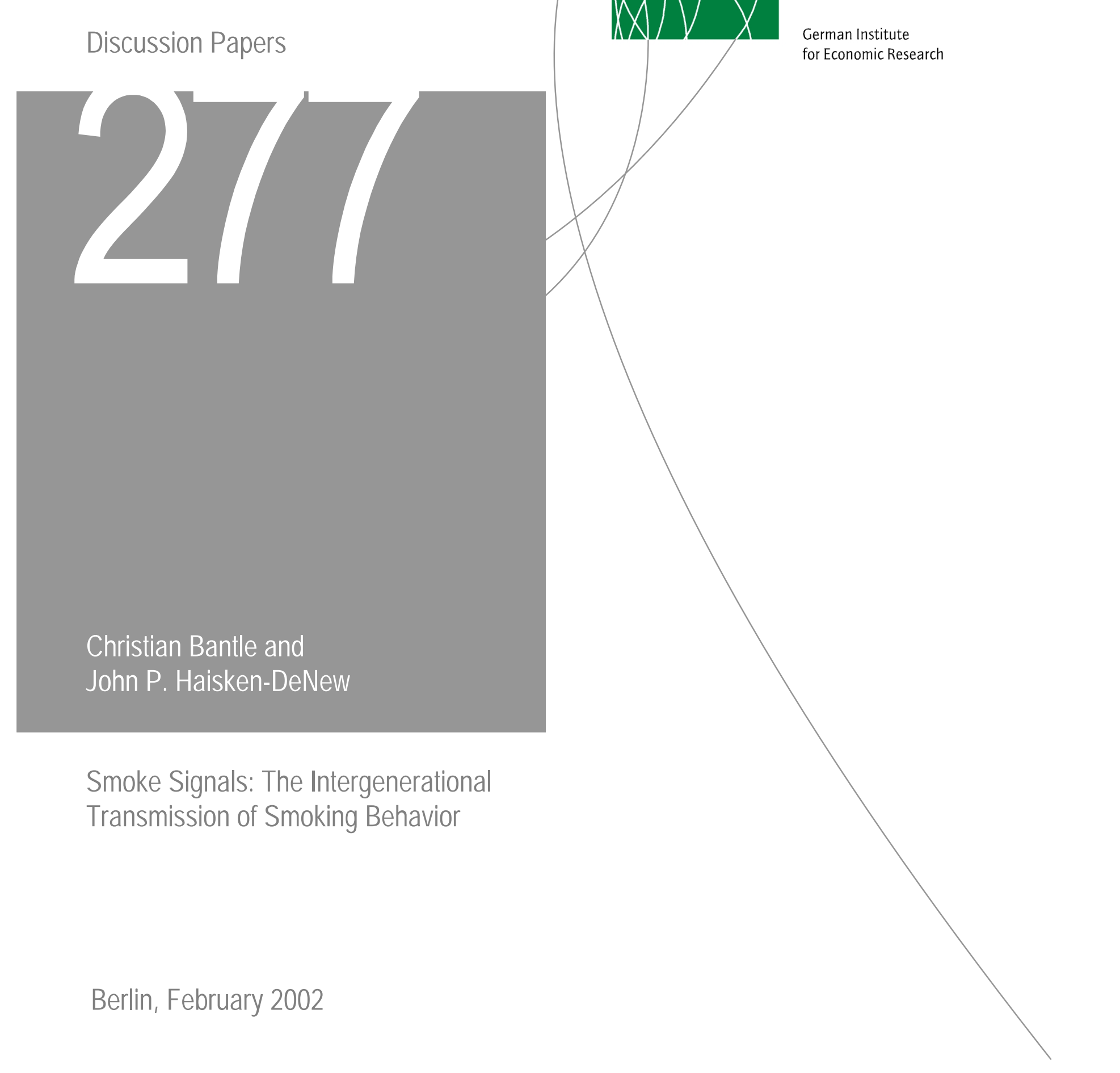


Opinions expressed in this paper are those of the author and do not necessarily reflect views of the Institute.

\section{DIW Berlin}

German Institute

for Economic Research

Königin-Luise-Str. 5

14195 Berlin,

Germany

Phone $+49-30-89789-0$

Fax +49-30-897 89-200

www.diw.de

ISSN 1619-4535 


\title{
Smoke Signals: The Intergenerational Transmission of Smoking Behavior
}

\author{
Christian Bantle \\ DIW Berlin \\ and \\ John P. Haisken-DeNew* \\ DIW Berlin and IZA Bonn
}

\begin{abstract}
In this paper, we investigate the intergenerational transmission of smoking behavior from parents to their children using data from the German SocioEconomic Panel, surveyed in 1999 including 813 youths aged 16 through 19. We find strong evidence, that parental smoking significantly increases the probability that their children likewise become smokers. Youths living in families with both parents smoking are 3.3 times more likely to smoke themselves, while a smoking father raises the probability by the factor 2.8 and a smoking mother by the factor 2.1 . Further, we treat single-parent households separately and control for other socioeconomic factors concerning the youths' smoking decision like household income, educational status and working status. Youths' leisure activities and personal attitudes are taken into consideration to test for determinants influencing youth smoking outside from the family context. Thus policies targeted at reducing juvenile smoking may fail, if parents' behavior is not taken into account.
\end{abstract}

\section{*Contact Address}

John P. Haisken-DeNew

DIW Berlin

Koenigin-Luise-Str. 5

14195 Berlin

Germany

Fax: +49-30-89789-109

Email: jhaiskendenew@diw.de

Keywords: Intergenerational Transmission, Smoking, Family Composition, GSOEP JEL: I12, J12, J13

Thanks go to Gert G. Wagner for helpful comments. 


\section{Introduction}

In recent years, youth smoking has moved increasingly into the focus of scientific and empirical research. Today, smoking and its consequences are one of the leading cause of premature death in western industrialized countries and although information about health risks and negative consequences of smoking have been increasingly disseminated in society over the past years, smoking rates in general persist at a high level in Germany, amounting to approximately $28 \%$ of the population aged 15 and older in the 1990s. Far more alarmingly, youth smoking rates among 15-20 years old adolescents rose in the same time period from $18 \%$ in 1992 to $25 \%$ in 1999, according to the German Federal Statistical Office (2000).

In that context, the question is, why do youths smoke or why do they still start smoking in such large numbers? In this paper, we concentrate not only on intergenerational transmission effects in particular explaining youth smoking, but also control for other socioeconomic factors and youths leisure activities.

According to the German Federal Statistical Office (2000), based on the 1999 German Microcensus, the average starting age is 19 years for male smokers and 20 years for females, whereas for persons in their late twenties, only negligible shares of population start smoking. This implies that the majority of smokers has started smoking as teenagers, thus at a time at which most teenagers still live with their parents. Intergenerational transmission effects, i.e. parental smoking behavior influencing their children likewise to become a smoker and therefore leading to persisting smoking rates over time, seem to be playing an important role in explaining smoking behavior in society as a whole.

The reasons for intergenerational transmission are complex. On the one hand, parents act as a role model in childhood and adolescence, even if adolescents rebel against their parents' behavior in puberty. On the other hand, parents might attempt to impose restrictions on their children wanting to start smoking. However if the parents themselves are smokers, then obvious credibility issues arise. As socio-economic factors explaining youth smoking, we examine the family setting, which means traditional two-parent families or single-parent households on the one hand and working status of the parents including per-capita household income on the other. Furthermore, educational standard of the youths and parental education is taken into consideration as well as the working status of the youths, in case they have already left school. Finally we test for a set of variables, which are not related to householdspecific characteristics mainly including different regular leisure activities as well as general 
future expectations, self-reported health status, life-satisfaction and being in a serious relationship.

In section II, we describe the factors concerning the smoking decision of adolescents in general and investigate sources of bounded rationality and parental influence. In section III, the German Socio-Economic Panel (GSOEP) dataset and the selection of explanatory variables is described and descriptive results for smoking behavior in Germany in general and youth smoking behavior in particular are given. Section IV then provides an empirical investigation of the influence that parental behavior, socio-economic factors and leisure activities exert on youth smoking, using logit regression techniques. In section $\mathrm{V}$, conclusions are drawn from the empirical evidence.

\section{Adolescents' Smoking Decision and the Role of Parents}

Part of the theoretical economic literature on smoking treats the smoking decision as a rational consumer decision, in which forward-looking individuals maximize their lifetime utility, taking monetary costs, withdrawal effects in case of quitting and future health risks into account. This theoretical view was developed by Becker and Murphy (1988), known as the "rational addiction model" and later applied to smoking and empirically tested by Chaloupka (1991), Labeaga (1993) or Becker et al. (1994). As a result of an individuals' rational decision-making process, one can become a smoker even knowing the long run negative implications of smoking - it is merely a question of discount rates.

Some authors extended the model and showed that the ex ante optimal decision to smoke might become sub-optimal in an ex post view. Some smokers are then locked-in to an unwanted or unintended pattern of behavior or in other words, they regret ever having started as discussed in Orphanides and Zervos (1995) and Suranovic et al. (1999).

However, it is questionable if smokers in general and youth smokers in particular can be treated as completely rational consumers. Laux (2000) casts doubt on assuming complete rationality, supporting his hypothesis with empirical results comparing the discount rates consumers reveal in their consumption of tobacco products goods with the discount rates they reveal in their savings and investment. Those discount rates differ significantly and he concludes that either consumers have unstable preferences or they are only partially rational, in that they behave rather as myopic than forward-looking individuals. Gruber (2000b) extends the argument by introducing a "projection bias", i.e. the propensity of youths projecting their current moment's preferences onto their future tastes due to a lack of life 
experience, as a source of bounded rationality. Further, he finds that young smokers are likely to underestimate the probability that they will still be smoking in the future, using data from the U.S. Department of Health and Human Services. High school seniors were asked for their future expectations on their smoking status and 56\% among the smokers stated they would not be smoking in 5 years. However, Gruber (2000a) finds that only one third of them had actually quit 5 years later.

There seem to be some more reasons to assume bounded rationality for the decisionmaking process in the case of smoking. Thus we will more precisely illustrate the factors which determine the smoking decision focusing on youth smoking behavior. Those factors include the benefits and costs of smoking and related reasons for the assumption of bounded rationality, normative restrictions imposed by parents and exogenous determinants such as education and household income as a measure for social status.

\section{A. Benefits from Smoking}

In fact, there is no biological human need to smoke, but people still chose to do so and most start in their teenage years. A young person not having smokers in his/her environment would have accordingly little incentive to smoke, and any supposed benefits would be non-existent or unknown. The incentive to smoke is only generated by one's environment and the benefits from smoking predominantly have a symbolic character. Children and youths watching their parents or friends smoke recognize the social function of tobacco products. Furthermore, they learn about attitudes towards smoking if parents or friends talk about it in their presence. Lopez (1983) locates the parental influence through transferring the patterns of signification of smoking to their children already in early years. Later on, around the age of twelve, peers become more influential in a teen's socialization and a new role model of orientation for norms and values.

Von Laffert (1998) investigates two sources of bounded rationality derived from the parental behavior which are already founded in early childhood: the utility conjecture and the illusion of high utility. If at least one parent smokes, utility conjecture suggests that infants believe smoking to have a positive utility simply because their parents do it, even if the exact nature of the utility is not directly obvious to them, perhaps promoting curiosity and provoking experimenting with smoking later on. From the infant's view, he/she expects that the persons taking care of him/her are acting in a reasonable manner. The illusion of high utility occurs if a child or a youth realizes that smoking is harmful. Assuming the utility 
conjecture and due to the widespread use of tobacco products in society, a child or youth assumes that although smoking imposes costs, the derived utility must even be higher and no matter which cost perception they have, they must believe in a positive cost-benefit relation. The latter still exists in an early stage of tobacco experimentation, because even then, the utility of smoking only partly becomes obvious and to a certain extent still has to be derived from the observation of others. Both arguments lead to an overestimation of the utility of smoking and might influence youths' decision to smoke.

Taking peer groups into consideration, smoking of adolescents has an image building function and cigarettes represent an effective medium to picture this image. As long as society relates smoking to attributes like "coolness", freedom, independence, rebelliousness or being mature and "grown-up" and reinforced by tobacco advertising or cinema movies, young people will be open for such examples and identify with them, especially as adolescents in puberty look for role models and therefore use examples prevalent in their daily life. Furthermore, smoking effectively allows one to distinguish oneself from others, define group membership and thus support socialization in that group.

Smoking can be used as a medium for non-verbal communication as discussed in Von Laffert (1998). Benefits then result from group membership or vice versa from not being excluded. In that case, network effects occur, which exist if one's own benefit from smoking increases, the more people around one likewise smoke. This often leads to homogeneous "cliques" in which either no one smokes or everyone smokes. Significant peer effects are reported by Charlton and Blair (1989) for Great Britain, by Oygard et al. (1995) using the Oslo Youth Study and by Gaviria and Raphael (1997) and Smith and Stutts (1999) for the U.S., who furthermore outline the fact, that peer pressure to smoke becomes weaker in late adolescence. Oygard et al. (1995) additionally report in their longitudinal study, that peer effects are no significant predictor for smoking in adulthood ten years later while mother's smoking remains the only significant long-term predictor for smoking. Their findings underline the importance of parental behavior in the long-run and support the argument of parental smoking leading to the persistence of smoking rates in society via intergenerational transmission effects.

Suranovic et al. (1999) shows that benefits arising from pharmacological effects like stimulation or relaxation as well, usually do not occur until patterns of physical addiction are well established and therefore their relevance for the initial smoking decision is rather low. In addition, most adolescent smokers report, they had to force themselves to smoke in the 
beginning because of the unaccustomed foul taste, feeling sick or developing headaches as discussed in Lopez (1983).

\section{B. Financial Costs}

The total costs of youths' smoking are on the one hand financial in nature and potential future health risks on the other. It should be postulated that financial costs indeed play an important role in the smoking-decision process of an adolescent because of a youth's typically binding budget constraint, relative to working adults. In fact, several studies for the United States report a strong negative impact of price on youths smoking participation, as in Gruber (2000a), Gruber and Zinman (2000), Gilleskie and Strumpf (2000). However, these studies also show, that younger teens' demand for tobacco products is price inelastic in the early experimentation and smoking initiation phase. Those findings are supported by Emery et al. (2001) examining experimentation with smoking in particular. They report that higher cigarette prices cannot prevent youths from smoking, but they may slow the progression towards addiction for some adolescents or delay the transition to habitual smoking because of smaller quantities being smoked. Financial costs do indeed matter when smoking patterns are established, but they are not that important in the beginning of a smoking career when cigarettes are obtained by friends and the quantity smoked is relatively low.

\section{Future Health Risks}

Today it is undisputed that sustained smoking does considerable damage to one's health and dissemination of that knowledge in society is rather high, given that it is even written on every tobacco product in nearly all western countries. However, apart from relatively trivial consequences like discoloring of teeth or shortness of breath, well-known serious health consequences such as lung cancer or cardiovascular diseases can become apparent only after a long period of smoking. Thus, smoking can be viewed as a potentially hazardous consumption activity or as risky behavior. According to Von Laffert (1998), negative health consequences in the future do not have much relevance for the initial smoking decision, although Lopez (1983) shows that young smokers often have better information on the risks involved than young non-smokers. Therefore, Von Laffert (1998) cites three reasons: first, the statistical risk is not applied to oneself (the well-known "it won't happen to me" syndrome). Add to this, many young smokers are convinced they can stop smoking whenever they want 
or expect themselves to do so in the near future, as noted above. Secondly, youths overly discount the future or in other words, the expected health damage lies too far in the future and appears too abstract, especially because most youths have little information concerning serious diseases. Thirdly, the relative significance of smoking risks will be underestimated in relation to other life threatening risks like environmental destruction, food-poisoning scandals or being involved in a fatal car crash which are also widely discussed in public. This might lead to the attitude, that smoking, being just another risk in an uncertain world, does not matter that much, although Viscusi (1991) finds that risk perception of the smoking risk is rather high in absolute terms and younger people tend to overestimate the actual risk in comparison to the population at large.

\section{Restrictions}

Restrictions concerning youth smoking can be divided in legal restrictions and those imposed by parents or other associated persons. Several studies for the US examine the effectiveness of legal restrictions such as access restrictions for adolescents or smoking bans in public areas on youths smoking as in Chaloupka and Wechsler (1995), Chaloupka and Pacula (1998), Chaloupka and Tauras (1999) or Czart et al. (2001). For the case of Germany, youth access restrictions for adolescents under 16 years do exist legally, but enforcement is relatively weak due to extensive availability of cigarette vending machines on the street. Additionally, only weak public smoking bans are implemented and nevertheless, the legal right to smoke at the age of 16 (even in specially designated areas in schools) might explicitly support smoking initiation after having reached this age to demonstrate perceived "grown-up" behavior.

Thus, restrictions imposed by parents and other authority figures having a strong influence on teens should not be neglected. If parents ask their children not to smoke, the enforcement of this restriction is twofold. On the one hand, it is a question of actual ability to control. On the other hand, parents imposing restrictions on their children have reduced credibility, if they are smokers themselves. Therefore, one needs to examine youth behavior in relation to parental presence in the household. We suggest, that if both parents (or in case of a single parent household the parent present in the household) have a full time working status, their ability to monitor and thus control the children's behavior are weaker. Gaviria and Raphael (1997) as well as Emery et al. (2001) find evidence that adolescents living with a single parent are more likely to establish smoking participation while Gilleskie and Strumpf (2000) find no significant impacts regarding the family situation. 


\section{E. Education and Social Origin}

The educational status of the parents and the household income as background characteristics determining the smoking decision have been dealt with repeatedly in the smoking literature. Regarding background characteristics as exogenous factors influencing intergenerational transmission effects, parents' educational status and the available per-capita-household income can play a role. It is hypothesized, that better education promotes a better understanding of the risks and dangers and permits better access to reliable information concerning smoking. Kenkel (1991) as well as Sander (1995) report that schooling has a significantly negative effect on adult smoking. Furthermore, Chassin et al. (1996) and Clark and Etilé (2001) report that higher education alters the quit probability in later years supporting the hypothesis that educational status rather influences the decision to quit than the decision to start smoking. In that sense, schooling as a determinant to lower smoking participation in general and higher quit probabilities in later years taken together lead to lower smoking rates amongst higher educated parents and therefore might influence youths attitude towards smoking and lead to lower smoking rates amongst their children as well.

Gruber and Zinman (2000) only find sparse evidence for a significant relevance of parental income and educational status for the adolescents smoking decision. A positive correlation between parents education and smoking participation of their children is evaluated by Chaloupka and Wechsler (1995) having used data from a survey of students in U.S. colleges and universities, which stands in contrast to the above stated hypothesis. Emery et al. (2001) do not find any significant influence determined by parental education or household income on the smoking participation of youths above 14 years.

Apart from the parents' educational status, the adolescents' educational status must be stressed as well, suggesting that schooling also improves their own perception of smoking risks and leads to a better understanding of the relation between healthier life-styles and better health outcomes.

Considering the determinants influencing the adolescent's decision-making process concerning whether to smoke, it becomes obvious that youth smoking results from several factors. In our opinion, parental smoking behavior has a non-negligible impact on youths likewise becoming a smoker owing to the parents function as an example, the consequential creation of utility conjecture as well as illusion of a high utility in the child's mind and the parents dilemma of credibility. In that way, youth smoking is not just a straightforward 
consequence of parental smoking behavior. The parent's smoking might simply lower the youth's inhibition threshold deciding whether to smoke as well. Intergenerational transmission then encourages youth smoking and leads to persisting smoking rates in society.

Therefore, the main purpose of this paper is to evaluate parents influence on youths' smoking behavior. This concern was highlighted by several papers, which confirm the positive relationship between parental smoking and adolescent smoking initiation as in Borland and Rudolph (1975) and Smith and Stutts (1999). Charlton and Blair (1989) can only support the existence of intergenerational transmission effects from the parents to their daughters, while Oygard et al. (1995) report the father-daughter relation as the only significant transmission channel of smoking behavior.

In our study, we particularly investigate the influence parental smoking has on their children taking current smoking behavior as well as former smoking behavior into account. Moreover, as far as we know, it is the first study combining parental and youth smoking behavior on the basis of current data for the case of Germany.

\section{Data}

The German Socio-Economic Panel (GSOEP) is a household panel data set from 1984 to the present consisting of some 14,000 individuals and roughly 7,000 households living in West Germany (the "old states") and East Germany (the "new states"). See Wagner, Burkhauser and Behringer (1993) for an overview. Foreigners and recent migrants are also included in the sample. The data analyzed here stem from the 1999 wave of the GSOEP.

In 1999 for the first time, the following smoking question was asked of all adult respondents (16 years and older) in the household: "Do you smoke? e.g. cigarettes, pipes or cigars", allowing three possible responses: (a) "Yes", (b) "No, but I used to smoke" and (c) "No".

For the purpose of this study, we concentrate on youths aged 16 through 19 still living in their parents' household to "ensure" the daily contact between youths and their parents. In the 1999 GSOEP sample, there are 924 youths aged 16 through 19, whereby 90 juveniles already left home and another 4 juveniles refused to answer the question, leaving 830 adolescents in our data set.

In Table 1, we present the weighted smoking rates by age of the youths still living at home. If the adolescents, which already moved from the parents household are included, the 
overall smoking rate is slightly higher due to the fact, that mainly the older ages, which are more likely to smoke, leave home.

Table 1: Smoking Behavior by Age in \% (Weighted Descriptive Statistics)

\begin{tabular}{|c|ccc|ccc|ccc|}
\hline \multirow{2}{*}{ Age } & \multicolumn{3}{|c|}{ Smokes } & \multicolumn{3}{c|}{ No, quit } & \multicolumn{3}{c|}{ No, never } \\
& total & Males & Females & total & Males & Females & total & Males & Females \\
\hline 16 & $\mathbf{2 9 , 9}$ & 28,3 & 31,5 & $\mathbf{1 , 6}$ & 1,9 & 1,3 & $\mathbf{6 8 , 5}$ & 69,8 & 67,2 \\
17 & $\mathbf{4 0 , 0}$ & 36,6 & 43,8 & $\mathbf{4 , 3}$ & 1,0 & 8,0 & $\mathbf{5 5 , 7}$ & 62,4 & 48,2 \\
18 & $\mathbf{3 6 , 0}$ & 39,5 & 32,0 & $\mathbf{2 , 4}$ & 3,3 & 1,5 & $\mathbf{6 1 , 5}$ & 57,3 & 66,6 \\
19 & $\mathbf{4 0 , 5}$ & 41,0 & 39,8 & $\mathbf{2 , 0}$ & 1,9 & 2,0 & $\mathbf{5 7 , 6}$ & 57,2 & 58,1 \\
\hline \multirow{2}{*}{$16-19$} & $\mathbf{3 6 , 1}$ & 35,9 & 36,3 & $\mathbf{2 , 6}$ & 2,0 & 3,3 & $\mathbf{6 1 , 3}$ & 62,1 & 60,5 \\
\hline \hline \multirow{2}{*}{ Total Population } & \multirow{2}{*}{$\mathbf{3 1 , 6}$} & 39,0 & 25,0 & $\mathbf{2 1 , 1}$ & 26,9 & 15,9 & $\mathbf{4 7 , 4}$ & 34,1 & 59,1 \\
\hline
\end{tabular}

Source: Own Calculations, GSOEP 1999.

In the total population aged 16 and older, $31.6 \%$ consider themselves to be smokers, with higher smoking rates for male respondents (39.0\%). Examining the age cohorts, the smoking rate raises to its peak for the 21 through 25 years old (44,2\%), further stays at a high level until the age 41-45 and then declines constantly. The obviously higher youth smoking rates and the higher total smoking rates in comparison to the results of the German Federal Statistical Office (2000) can be traced back to different age cohorts. The Federal Statistical Office includes youths aged 15 not included in our data set and who show noticeable lower smoking participation rates.

The descriptive results in Table 1 show, that smoking initiation mainly takes part in adolescence, even if the fluctuation of smokers or cohort effects are not taken into consideration. Douglas and Hariharan (1994) as well as Douglas (1998) note similar findings in investigating the hazard rate of starting smoking. They report a strong rise in adolescence peaking at the age of nineteen and then sharply declining until the late twenties.

In the binary logit regression analysis, the dependent variable 'Youth smoking behavior', is defined as currently smoking or not. Consequently, we treat former adolescent smokers as non-smokers, even if they still might be at-risk-smokers. However, the answer "No, quit" can be regarded as a result of a decision-making process, in which youth had once 
been experimenting with smoking, but due to their own experience, decided to quit. In such cases, parental smoking behavior could have influenced youths in starting to experiment, but this did not lead to regular smoking habits.

\section{A. The Role of Parents}

We hypothesize that the behavior of the 'parents' present in the household is relevant for the investigation into the intergenerational transmission of smoking behavior. Therefore, 'parents' in our context also include husbands or wives in second marriage as well as life companions living in the household, even if they are not the biological parents of the youths living in that household. We have done so, because we primarily treat the intergenerational transmission of smoking behavior as a social interaction between parents and youths for which the behavior of the daily present parents is decisive, especially if the parents are trapped in the dilemma of credibility or trying to enforce restrictions. It should be noted, that in case of a non-biological parent, the above noted reasons for bounded rationality in early childhood, i.e. utility conjecture and illusion of high utility might become ineffective for a small number of observations.

To examine the intergenerational transmission of smoking behavior, we distinguish between households with only the father smoking and the mother not, those with only the mother smoking and the father not, and those with both parents smoking, taking households with non-smoking parents as the reference group. Furthermore, past parental smoking behavior is taken into consideration using the same differentiation. To distinguish the case in which only one parent in a two-parent traditional family smokes from those with a smoking single-parent, we use interaction terms regarding the family situation. In our data set, we have 700 juveniles living in a two-parent traditional family and 130 living in a single-parent household, where 109 live with its mother and 21 with the father. Due to the small number of the single-father households, these empirical results are questionable.

Table 2 shows the descriptive results regarding youth smoking behavior with respect to the parents' behavior. Apparently, parental smoking noticeably raises youth' smoking participation from $22.0 \%$ for adolescents living in a household, in which both parents do not smoke, up to $45.1 \%$ for the case of two smoking parents. In the single-parent households, youth smoking is obviously higher irrespective of the parents' smoking behavior. Further, gender specific transmission channels seem to be worth considering. In traditional two-parent families with only the father smoking, smoking by girls is distinctly higher than that of boys, 
whereas in case of only the mother being a smoker, smoking rates for boys are higher. In single-mother households, youths' smoking is the highest regardless of gender, however in addition, girls are more likely to smoke than boys. Therefore, we suggest that gender specific transmission particularly happens from fathers to their daughters and vice versa.

Table 2: Youth smoking behavior by parental behavior (Weighted Descriptive Statistics)

\begin{tabular}{|l|c|cc|}
\hline \multirow{2}{*}{$\begin{array}{l}\text { Parental smoking } \\
\text { behavior }\end{array}$} & Total & Males & Females \\
\cline { 2 - 4 } Traditional Families: & & & \\
Parents do not smoke & 22,0 & 23,3 & 20,3 \\
Only Father smokes & 40,8 & 32,3 & 48,3 \\
Only Mother smokes & 40,0 & 53,0 & 25,0 \\
Both Parents smoke & 45,1 & 51,2 & 39,8 \\
Single-Parent Families: & & & \\
Single Father does not smoke & 27,2 & 47,1 & 8,4 \\
Single Father smokes & 36,7 & 21,0 & 58,4 \\
Single Mother does not smoke & 38,8 & 33,7 & 71,6 \\
Single Mother smokes & 69,8 & 67,6 & \\
\hline
\end{tabular}

Source: Own Calculations, GSOEP 1999.

\section{B. Socio-Economic Factors}

Introducing a second set of explanatory variables, we focus on socio-economic factors, which are not directly related to smoking. On the one hand, as background characteristics, we observe the post-governmental household income as a measure of economic status, the household size and the consequential per-capita income. Furthermore, we observe the education level of that parent with the highest education measuring the years of schooling as independent variable, no matter which path of education they followed (no matter which kind of education they received). Additionally, we test for the working status of the parents suggesting with both parents having a full-time working status, they have lesser control possibilities if they wish their children not to smoke.

On the other hand, youth related socio-economic factors are observed. First, we take the kind of school, the adolescent attends at present or the kind of school graduation 
certificate he/she received as an indicator for its level of education. In Germany there is a divided secondary school system principally consisting of three different types of school. The decision which school to visit is generally made after finishing the basic primary school at the age of ten. Then, the decision is made whether to attend the basic level (Hauptschule), which ends up after 9th class (age 15), the intermediate level (Realschule) ending up after 10th class (age 16) allowing for higher apprenticeships or the advanced level (Gymnasium), which is finished after 13th class (age 19) and allows one entrance into university. It should be noted, that it is still possible to change the type of school later on, coupled with an aptitude test in case of an upwards shift. Hauptschule is defined to be the reference group in the analysis. Secondly, we observe the working status of the adolescents as a grouped variable, making a distinction between 'not working at all' as the reference group, 'working', no matter if parttime or full-time, 'being in a apprenticeship' or 'rendering military/civil service'.

\section{Activities and Attitudes}

As a third set of explanatory variables, we use leisure activities of youth and attitudes towards life including self-reported life satisfaction (on a scale from 0 to 10), expectations about the future in general (being optimistic) and the concern towards one's own health (very or somewhat concerned vs. not concerned at all) as well as the self-evaluated health status (on a scale from 1 to 5). As noted above, peer behavior, which youths mainly observe in their freetime, obtains a relevant importance in adolescence offering additional role models to the existing patterns of parental behavior. Therefore, these variables are introduced to check for parent-unrelated factors on the one hand and to find alternative explanations for youth smoking behavior derived from their social interaction outside the household on the other.

Concerning leisure activities, the respondents give information on the frequency of certain activities. We treat weekly participation as a regular practice for the following cases: 'Doing active sports', 'Going to cinemas, pop concerts, discos or sporting events', and 'Being with friends'. In case of 'Church-going' and 'Visiting cultural events like concerts, theatre or presentations', we define monthly practice as regular. Regarding 'Honorary office participation in clubs, associations or social services' and 'Participation in public initiatives, political parties or local government', we distinguish between those being engaged, even if only sometimes and those who are never active in those activities. Not as an activity, but as a personal factor for one's own life-situation, we take the question for being in a serious relationship into account. 


\section{Application}

The empirical analysis is implemented using the logit regression procedure. In model (1), we only test for the parental smoking behavior and the family situation by interaction. In the model (2), we add household characteristics and socio-economic factors to the model, before variables concerning leisure activities and personal attitudes are introduced in model (3) to test for household-unrelated determinants. Far more, this extension acts as an indicator for the robustness of the results drawn from the base model on the one hand and allows us to draw some conclusions concerning peer effects on the other. Although not reported, all specifications include variables reflecting age, gender, nationality (German vs. foreign), region of origin ("old" states vs. "new" states) and living in a large city (500,000 and over). Finally, gender specific transmission channels of smoking behavior are investigated. The regression results are presented as Odds Ratios showing the multiplier of the probability of being a smoker in comparison to the reference group, which means values greater than 1 represent a higher probability of being a smoker and values smaller than 1 diminishes the smoking probability.

\section{A. Results}

Column (1) of Table 3 presents the results for model (1). In this specification, parental smoking has a strong influence on youths' behavior no matter if only one parent smokes or both with all odds ratios being significant at the $1 \%$ level. The probability of being a smoker living in a complete family is 2.5-times higher if only the mother smokes while a smoking father even raises that probability by the factor 3.6. The highest odds ratio is estimated for families in which both parents smoke with a smoking probability 4.4 times higher. In that first model specification, living in a single parent household likewise significantly raises the adolescents smoking probability regardless of parental smoking behavior. Taking a closer look at single-parent households, the results for the single fathers are not very meaningful due to the small number of observations like noted above. However, testing single-mother households leads to reliable results and the smoking probability of those juveniles living alone with a smoking mother approximates living in a complete family in which both parents smoke. 
Even a father who used to smoke in the past still more than doubles the smoking probability for his children. This result underlines the arguments for bounded rationality of an juvenile caused by former parental imprint.

Introducing background characteristics and socio-economic factors, the odds ratios concerning parental smoking behavior slightly decline but the relationship between them remains stable. Only youths living with a single-mother are even more likely to smoke than in the base model estimation. Though the extension reduces the significance level in case of a smoking mother and a formerly smoking father, but the results are still glaring at a higher significance for the complete model. Regarding the background characteristics, neither the educational status of the parent with the longest period of education nor household size, income and per-capita income influence significantly the youths' smoking decision. Even if higher educated adults are less likely to smoke in our data set, there is no evidence, that a better perception of smoking risks and better access to reliable health information of the parents influences youths behavior.

One explanation might be, that health experiences have to be made on one's own ${ }^{1}$. We can also support the fact of higher quit probabilities for higher educated parents regarding the correlation coefficients. Only treating the smoking-related variables, parental education shows the highest positive correlation coefficient for the case of both parents being formerly smokers and it is even higher than that for both parents never having smoked. However regardless of the reasons for higher quit probabilities amongst higher educated adults, those arguments only concern the parents and not their children.

Furthermore, we did not find evidence for the suggestion, that full-working parents irrespective of family situation have lesser control possibilities to prevent their children from smoking if they wish them not to smoke. Though the probability is slightly increased, the hypothesis has to be rejected. A problem about this question is, that we are not able to identify the type of restrictions imposed by parents on their children.

Examining school attendance and working status of the adolescents opens up further insights in youth smoking behavior. Having a job or being in an apprenticeship significantly increases the probability of being a smoker by factor 2.4 and 2.0 respectively, in relation to non-working youths. One explanation might be, that those juveniles have a higher disposable income in comparison to those still attending school and therefore they can afford to buy

\footnotetext{
${ }^{1}$ Alternatively following Chassin et al. (1996), lower smoking rates for higher educated people are a consequence of higher quit probabilities caused by increased social pressure existing in occupational fields requiring higher education while Harris and Harris (1996) argue, that better educated people obtain higher retirement earnings on average and hence face a greater loss of lifetime earnings in case of premature death which makes them more likely to quit.
} 
cigarettes. However, the result should be seen in conjunction with the results concerning school attendance. The smoking probability of adolescents attending Gymnasium, is more than cut by half in comparison to those having graduated Hauptschule. Taking the type of school as a measure for the educational status, higher education significantly lowers smoking participation.

In our opinion, reducing this result only to the educational status is too short-sighted due to the heterogeneity of youths aged 16 through 19 with respect to their daily preoccupation. Adolescents attending the Hauptschule or Realschule usually graduate at the age of 15 respectively 16. Afterwards, most of them start an apprenticeship which is associated with a change in their social environment including more contact with older persons and an earlier entry into the labor market, in comparison to their peers attending Gymnasium. In that case, new patterns of socialization are experienced and again new role models can be observed. Due to that change of life-situation, those reasons might induce some adolescents to start smoking. Although the results are striking, explanations should be drawn with caution due to the heterogeneity of youths at that age, considering the fact that they are either still go to school or already gaining occupational experience.

In our third specification, leisure activities and personal attitudes are added to investigate factors influencing the smoking decision detached from the context of the household. Regarding leisure activities, the likelihood of being a smoker is nearly cut in half for youths regularly doing sports and for those going to church regularly, the probability is even reduced to one third compared to those rarely or never going to church. Active sports and church-going are thus strong predictors of not smoking among youths. Additionally, being engaged in clubs, associations or social services reduces the smoking probability, but only insignificantly.

On the other hand, for those juveniles answering social interaction with friends as regular activity, the likeliness of being a smoker is nearly doubled. Additionally, being in a serious relationship increases smoking likelihood as well, but not significantly. Although we do not have any information about the peers' smoking behavior, those results suggest, that peer-effects do have importance with regard to smoking. Lastly, even if visiting cultural events regularly and engagement in public institutions lowers the smoking probability and regular visits of cinemas or dancing events raises the probability, they can not be treated as reliable predictors.

Comparing this model with our second specification, the introduction of new variables leaves the results concerning parental smoking behavior nearly. In families with both parents 
smoking, the probability that the children likewise smoke is 3.3-times higher. A smoking father raises the smoking probability by factor 2.8 while only the mother smoking in that household still doubles the youths' smoking probability. Regarding families in which the father used to smoke in the past, smoking probability for the adolescents is likewise noticeable increased.The odds ratios for school attendance and youth' working status only slightly change, but attending Gymnasium is no longer a significant predictor for not smoking. This can be explained bythe fact, that attending the Gymnasium is positively correlated to all leisure activities, while attending the Hauptschule shows negative correlation coefficients except for the regular social interaction with friends. Therefore, the effect caused by the activity variables influences the odds ratios concerning the school attendance variables. As a result, it becomes obvious, that the adolescents educational status only represents a weak factor in explaining youth smoking. Far more, education should be seen in conjunction with the social environment the youths are confronted with.

Taking personal attitudes into account, general life satisfaction as well as the concern towards one's own health have no apparent influence on smoking, but those being optimistic about the future in general are signigicantly less likely to smoke. On the other hand, those reporting poorer health have an increased smoking probability. It is not clear what the direction of causality is: whether smoking lowers their health status or if bad health induces smoking. However, it is unlikely that at that early age, smoking specifically would have a strong effect on youth's health.

Taken together, determinants independent from the household do matter and influence the youths' decision making process with regard to smoking. Notwithstanding intergenerational transmission of smoking behavior keeps its strong influence.

In a last step, we test for gender-specific transmission channels using interaction terms. In that case, only households with either only the father or only the mother being a smoker obviously obtain relevance to investigate gender-specific differences. Therefore, we tested the complete model including socio-economic factors and leisure activity, although only the results with respect to gender are reported in Table 3, column (4).

The highest odds ratio of 5.1 is estimated for girls living in a traditional two-parent family with a smoking father. Though fathers' smoking still has a positive impact on smoking participation of sons, it is far more weaker and insignificant. In contrast, a smoking mother raises the smoking participation of sons significantly by the factor 3.3 , but has no significant impact on their daughters smoking behavior. 
Those results suggest, that smoking behavior is mainly transmitted from fathers to daughters and from mothers to their sons.

\section{Conclusions}

In our study, we investigated the intergenerational transmission of smoking habits in Germany. Having used the GSOEP-dataset for the year 1999, we found strong evidence that parental smoking significantly raises the probability of smoking for their children. With both parents smoking, the probability is increased by the factor 3.3, while in case of a smoking father the smoking probability is 2.8 times higher. The weakest impact is given if only the mother smokes, but her behavior still more than doubles the likeliness that her children smoke. Taking past smoking behavior into account, a father who used to smoke also nearly doubles the youths' smoking probability and fosters the thesis, that not only current parental behavior influences adolescents, but also past behavior already negatively "imprints" adolescents in their childhood.

Regarding single-parents household which are overwhelmingly single-motherhouseholds, the results are even far more striking. The odds ratio for youths living with a single-mother who smokes is 6.8, representing the strongest predictor for smoking participation in our study.

Taking gender specific transmission channels into account, our results show that sons are more influenced by the mothers behavior while daughters seem to take the father as an example concerning the smoking behavior.

Furthermore, household-related background characteristics do not play an important role in the adolescents decision making process towards smoking. But a second field of relevance for youth smoking is represented by socio-economic factors directly concerning the adolescents and their leisure behavior. Pupils attending schools of higher education are less likely to smoke while in contrast, those leaving school earlier and starting an apprenticeship or having a full-time job are more likely to smoke. Observing the frequencies of certain leisure activities, we report a strong negative impact on smoking participation for those regularly active in sports reducing smoking probability to half and for regular church-goers even to one third. In contrast, those having frequent social interaction with their friends show higher smoking participation probabilities, providing evidence for the existence of network effects in regard of smoking and point out the importance of peer behavior.

Nevertheless, parental smoking behavior represents the strongest predictor for youth smoking participation in our study and therefore, we draw the conclusion, that smoking 
behavior is handed down from one generation to the next and as a consequence leads to persisting smoking rates in general. Thus, with respect to smoking, youths can not be seen as autonomous, rational consumers. Far more, they should be seen as individuals in their social context.

Directing the attention to public health policies, our findings offer a new aspect. Apart from activities which directly address to youths, e.g. access laws, educational campaigns in schools or youth-related anti-smoking advertisements, one should be aware of the potential diminishing youth smoking rates if adults can be brought to quit smoking.

Activities which aim at preventing youths from smoking should not merely focus on restriction and access laws, youth specific anti-smoking advertisements or educational campaigns in school. Furthermore the arising potential for diminishing youth smoking rates via diminishing smoking participation rates among adults must become aware to public health institutions as well as to parents. On the other hand, when evaluating anti-smoking campaigns for adults, the effect of lower youth smoking rates should also be taken into account. 


\section{References}

Becker, G.S., Murphy, K.M., 1988. A Theory of Rational Addiction. Journal of Political Economy 96, 675--700.

Becker, G.S., Grossman M., Murphy, K.M., 1994. An Empirical Analysis of Cigarette Addiction. American Economic Review 84, 396--418.

Borland, B.L., Rudolph, J.P., 1975. Relative Effects of Low Socio-Economic Status, Parental Smoking and Poor Scholastic Performance on Smoking among High School Students. Social Science and Medicine 9, 27--30.

Charlton, A., Blair, V., 1989. Predicting the Onset of Smoking Boys and Girls. Social Science and Medicine 29, 7, 813--818.

Chaloupka, F.J., 1991. Rational Addictive Behavior and Cigarette Smoking. Journal of Political Economy 99, 722--742.

Chaloupka, F.J., Wechsler, H., 1995. Price, Tobacco Control Policies and Smoking among Young Adults. NBER Working Paper 5012.

Chaloupka, F.J., Wechsler, H., 1997. Price, Tobacco Control Policies and Smoking among Young Adults. Journal of Health Economics 16, 359-373.

Chaloupka, F.J., Pacula, R.L., 1998. An Examination of Gender and Race Differences in Youth Smoking - Responsiveness to Prices and Tobacco Control Policies. NBER Working Paper 6541.

Chaloupka, F.J., Tauras J.A., 1999. Price, Clean Indoor Air Laws, and Cigarette Smoking: Evidence from Longitudinal data for Young Adults. NBER Working Paper 6937.

Chassin, L., Presson, C.C., Rose, J.S., Sherman, S.J., 1996. The Natural History of Cigarette Smoking from Adolescence to Adulthood: Demographic Predictors of Continuity and Change. Health Psychology 15, 478--484.

Clark, A., Etilé, F., 2001. The Effect of Health Information on Cigarette Consumption: Evidence from British Panel Data. mimeo.

Czart, C., Pacula, R.L., Chaloupka, F.J. and Wechsler, H. (2001): "The impact of Prices and Control Policies on Cigarette Smoking among College Students", Contemportary Economic Policy 19, 135--148.

Douglas, S., Hariharan G., 1994. The Hazard of Starting Smoking: Estimates from a Split Population Duration Model. Journal of Health Economics 13, 213--230.

Douglas, S. 1998. The Duration of the Smoking Habit. Economic Inquiry 36, 49--64.

Emery, S., White, M.M., Pierce, J.P., 2001. Does Cigarette Price Influence Adolescent Experimentation? Journal of Health Economics 20, 261--270. 
Gaviria, A., Raphael, S., 1997. School-based Peer Effects and Juvenile Behavior. Discussion Paper 97-21, University of California, San Diego.

German Federal Statistical Office 2000. 1999 Mikrozensus des statistischen Bundesamtes. Wiesbaden.

Gilleskie, D.B., Strumpf K.S., 2000. The Behavioral Dynamics of Youth Smoking. NBER Working paper 7838.

Gruber, J., 2000a. Youth Smoking in the U.S.: Prices and Policies. NBER Working paper 7506.

Gruber, J., 2000b. Risky Behavior among Youths: An Economic Analysis. NBER Working paper 7781.

Gruber, J., Zinman J. 2000. Youth Smoking in the U.S.: Evidence and Implications. NBER Working paper 7780.

Harris, W.T., Harris, L., 1996. The Decision to Quit Smoking: Theory and Evidence. Journal of Socio-Economics 25, 601--618.

Kenkel, D.S., 1991. Health Behavior, Health Knowledge and Schooling. Journal of Political Economy 99, 287--305.

Labeaga, J.M., 1993. Individual Behavior and Tobacco Consumption: A Panel Data Approach. Health Economics 2, 103--112.

Laffert von, G., 1998. Rauchen, Gesellschaft und Staat - Konsumanomalien, Wohlfahrtseffekte und staatlicher Regulierungsbedarf im Zusammenhang mit dem Zigarettenkonsum. Deutscher Universitaets-Verlag, Wiesbaden.

Laux, F. L., 2000. Addiction as a Market Failure: Using Rational Addiction Results to Justify Tobacco Regulation. Journal of Health Economics 19, 421--437.

Lopez, H., 1983. Rauchen bei Kindern und Jugendlichen - Eine empirische Untersuchung. Beltz Forschungsberichte, Weinheim und Basel.

Orphanides, A., Zervos, D., 1995. Rational Addiction with Learning and Regret. Journal of Political Economy 103, 739--758.

Oygard, L., Klepp, K.-I., Tell, G.S., Vellar, O.D., 1995. Parental and Peer Influences on Smoking among Young Adults: Ten Year Follow-up of the Oslo Youth Study Participants. Addiction 90, 561--569.

Sander, W., 1995. Schooling and Smoking. Economics of Education Review 14, 22--33.

Smith, K.H., Stutts, M.A., 1999. Factors that Influence Adolescents to Smoke. Journal of Consumer Affairs 33, 321--257. 
Suranovic, S. M., R.S. Goldfarb, Leonard, T.C., 1999. An Economic Theory of Cigarette Addiction. Journal of Health Economics 18, 1--29.

Viscusi, W.K., 1991. Age Variations in Risk Perceptions and Smoking Decisions. The Review of Economics and Statistics 73, 4, 577--588.

Wagner, G.G., Burkhauser, R.V., Behringer, F. 1993. The English Language Public Use File of the German Socio-Economic Panel Study. The Journal of Human Resources, 28, 2, 429-433. 
Table 3: Logit Estimation of Youth's Smoking Behavior

\begin{tabular}{|c|c|c|c|c|}
\hline & $(1)$ & $(2)$ & (3) & (4) \\
\hline East German & $\begin{array}{l}1.4220 \\
(1.670)^{*}\end{array}$ & $\begin{array}{l}1.2937 \\
(1.050)\end{array}$ & $\begin{array}{l}1.1308 \\
(0.450)\end{array}$ & $\begin{array}{l}1.2128 \\
(0.700)\end{array}$ \\
\hline Gender & 1.0762 & 0.9104 & 1.2139 & 1.2471 \\
\hline & $(0.360)$ & $(-0.440)$ & $(0.680)$ & $(0.770)$ \\
\hline large City & 0.8188 & 0.8667 & 0.9889 & 0.9514 \\
\hline & $(-0.560)$ & $(-0.370)$ & $(-0.030)$ & $(-0.130)$ \\
\hline Only Father Smokes & $\begin{array}{c}3.5889 \\
(3.700)^{*}\end{array}$ & $\begin{array}{c}2.9281 \\
(2.960)^{*}\end{array}$ & $\begin{array}{c}5.1024 \\
(3.540)^{*}\end{array}$ & $\begin{array}{c}4.9282 \\
(3.330)^{*}\end{array}$ \\
\hline Only Mother Smokes & $(2.580)^{*}$ & $\begin{array}{c}2.1655 \\
(2.130)^{*}\end{array}$ & $\begin{array}{l}1.4567 \\
(0.780)\end{array}$ & $\begin{array}{c}2.6547 \\
(2.230)^{*}\end{array}$ \\
\hline Both Mother and Father Smoke & $\begin{array}{l}4.4105 \\
(4.790)^{*}\end{array}$ & $\begin{array}{l}3.6239 \\
(4.020)^{*}\end{array}$ & $\begin{array}{l}3.4383 \\
(3.650)^{*}\end{array}$ & $\begin{array}{c}3.5577 \\
(3.750)^{*}\end{array}$ \\
\hline Only Father Previously Smoked & $\begin{array}{l}2.1655 \\
(2.580)^{*}\end{array}$ & $\begin{array}{l}2.1043 \\
(2.370)^{*}\end{array}$ & $\begin{array}{l}1.9942 \\
(2.200)^{*}\end{array}$ & $\begin{array}{l}1.7646 \\
(1.770)^{*}\end{array}$ \\
\hline Only Mother Previously Smoked & $\begin{array}{c}1.1306 \\
(0.320)\end{array}$ & $\begin{array}{l}1.0201 \\
(0.050)\end{array}$ & $\begin{array}{l}1.1307 \\
(0.300)\end{array}$ & $\begin{array}{l}1.1326 \\
(0.310)\end{array}$ \\
\hline Both Mother and Father Previously Smoked & $\begin{array}{l}1.6680 \\
(1.110)\end{array}$ & $\begin{array}{l}1.6794 \\
(1.110)\end{array}$ & $\begin{array}{c}2.1642 \\
(1.580)\end{array}$ & $\begin{array}{c}2.1748 \\
(1.600)\end{array}$ \\
\hline Single Parent & $\begin{array}{c}2.8205 \\
(2.400)^{*}\end{array}$ & $\begin{array}{c}2.1248 \\
(1.620)\end{array}$ & $\begin{array}{c}2.1539 \\
(1.610) \\
\end{array}$ & $\begin{array}{c}2.8469 \\
(2.650)^{*} \\
\end{array}$ \\
\hline Only Father Smokes \& Single Parent & $\begin{array}{c}0.3550 \\
(-1.080)\end{array}$ & $\begin{array}{c}0.3596 \\
(-1.010)\end{array}$ & $\begin{array}{c}0.3528 \\
(-1.010)\end{array}$ & -- \\
\hline Only Mother Smokes \& Single Parent & $\begin{array}{l}1.7557 \\
(0.890)\end{array}$ & $\begin{array}{l}2.6335 \\
(1.460)\end{array}$ & $\begin{array}{c}3.4991 \\
(1.890)^{*}\end{array}$ & -- \\
\hline Only Father Smokes \& Boy & -- & - & $\begin{array}{c}0.2775 \\
(-2.150)^{*}\end{array}$ & $\begin{array}{c}0.2561 \\
(-2.220)^{*}\end{array}$ \\
\hline Only Mother Smokes \& Boy & -- & -- & $\begin{array}{c}1.8819 \\
(1.160) \\
\end{array}$ & $\begin{array}{c}1.5651 \\
(0.840) \\
\end{array}$ \\
\hline Max Parental Education & -- & $\begin{array}{c}1.0152 \\
(0.300)\end{array}$ & $\begin{array}{l}1.0269 \\
(0.510)\end{array}$ & $\begin{array}{l}1.0120 \\
(0.210)\end{array}$ \\
\hline Household Income & -- & $\begin{array}{c}0.9947 \\
(-0.080)\end{array}$ & $\begin{array}{l}1.0265 \\
(0.420)\end{array}$ & $\begin{array}{l}1.0214 \\
(0.370)\end{array}$ \\
\hline Household Income $^{2}$ & -- & $\begin{array}{l}0.9999 \\
(-0.370)\end{array}$ & $\begin{array}{c}0.9999 \\
(-0.960)\end{array}$ & $\begin{array}{c}0.9999 \\
(-1.000)\end{array}$ \\
\hline Equivalent Person Income & -- & $\begin{array}{l}1.0071 \\
(0.050)\end{array}$ & $\begin{array}{l}0.9439 \\
(-0.460)\end{array}$ & $\begin{array}{c}0.9508 \\
(-0.440)\end{array}$ \\
\hline Equivalent Person Income ${ }^{2}$ & -- & $\begin{array}{l}1.0003 \\
(0.430)\end{array}$ & $\begin{array}{l}1.0007 \\
(1.040)\end{array}$ & $\begin{array}{l}1.0007 \\
(1.150)\end{array}$ \\
\hline Both Parents Working Full Time & -- & $\begin{array}{l}1.2205 \\
(0.790)\end{array}$ & $\begin{array}{l}1.1745 \\
(0.640)\end{array}$ & $\begin{array}{l}1.1380 \\
(0.520)\end{array}$ \\
\hline Household Size & -- & $\begin{array}{l}1.0567 \\
(0.170)\end{array}$ & $\begin{array}{c}0.9869 \\
(-0.040)\end{array}$ & $\begin{array}{l}1.0282 \\
(0.100)\end{array}$ \\
\hline Intermediate High School & -- & $\begin{array}{c}0.8958 \\
(-0.380)\end{array}$ & $\begin{array}{c}0.9782 \\
(-0.070)\end{array}$ & $\begin{array}{l}1.0195 \\
(0.070)\end{array}$ \\
\hline Advanced High School & -- & $\begin{array}{c}0.4490 \\
(-2.100)^{*}\end{array}$ & $\begin{array}{c}0.5059 \\
(-1.700)^{*}\end{array}$ & $\begin{array}{c}0.5808 \\
(-1.400)\end{array}$ \\
\hline Other School & -- & $\begin{array}{l}1.0783 \\
(0.210)\end{array}$ & $\begin{array}{l}1.3026 \\
(0.720)\end{array}$ & $\begin{array}{l}1.4186 \\
(0.970)\end{array}$ \\
\hline Full/Part Time or Marginal & -- & $\begin{array}{l}2.3808 \\
(2.560)^{*}\end{array}$ & $\begin{array}{l}2.8919 \\
(2.880)^{*}\end{array}$ & $\begin{array}{c}2.8370 \\
(2.860)^{*}\end{array}$ \\
\hline School / Training & -- & $\begin{array}{l}1.9908 \\
(2.650)^{*}\end{array}$ & $(2.890)^{*}$ & $\begin{array}{c}2.1373 \\
(2.820)^{*}\end{array}$ \\
\hline Military / Community Service & -- & $\begin{array}{c}0.2572 \\
(-1.190)\end{array}$ & $\begin{array}{c}0.3344 \\
(-0.860)\end{array}$ & $\begin{array}{c}0.3922 \\
(-0.780)\end{array}$ \\
\hline Gender & -- & $\begin{array}{c}0.8983 \\
(-0.960) \\
\end{array}$ & $\begin{array}{c}0.9443 \\
(-0.500) \\
\end{array}$ & $\begin{array}{c}0.9527 \\
(-0.420) \\
\end{array}$ \\
\hline Cultural Events & -- & -- & $\begin{array}{c}0.7320 \\
(-1.090)\end{array}$ & $\begin{array}{c}0.7383 \\
(-1.050)\end{array}$ \\
\hline Cinema / Dancing & -- & -- & $\begin{array}{c}1.4886 \\
(1.760)^{*}\end{array}$ & $\begin{array}{c}1.5301 \\
(1.860)^{*}\end{array}$ \\
\hline Sports & -- & -- & $\begin{array}{c}0.5741 \\
(-2.470)^{*}\end{array}$ & $\begin{array}{c}0.5689 \\
(-2.550)^{*}\end{array}$ \\
\hline Being with Friends & -- & -- & $\begin{array}{c}1.8661 \\
(2.060)^{*}\end{array}$ & $\begin{array}{c}1.8303 \\
(2.040)^{*}\end{array}$ \\
\hline Social Responsibility & -- & -- & $\begin{array}{c}0.6006 \\
(-1.980)^{*}\end{array}$ & $\begin{array}{c}0.6168 \\
(-1.890)^{*}\end{array}$ \\
\hline Political Involvement & -- & -- & $\begin{array}{c}0.9887 \\
(-0.020)\end{array}$ & $\begin{array}{c}0.9006 \\
(-0.220)\end{array}$ \\
\hline Attending Church & -- & -- & $\begin{array}{c}0.3425 \\
(-2.600)^{*}\end{array}$ & $\begin{array}{c}0.3361 \\
(-2.590)^{*}\end{array}$ \\
\hline Optimist & -- & -- & $\begin{array}{c}0.6488 \\
(-1.790)^{*}\end{array}$ & $\begin{array}{c}0.6828 \\
(-1.590)\end{array}$ \\
\hline Health of Parents & -- & -- & $\begin{array}{c}1.5406 \\
(2.870)^{*}\end{array}$ & $\begin{array}{c}1.4743 \\
(2.610)^{*}\end{array}$ \\
\hline Own Health Worries & -- & -- & $\begin{array}{c}0.9785 \\
(-0.090)\end{array}$ & $\begin{array}{c}0.9959 \\
(-0.020)\end{array}$ \\
\hline Life Satisfaction & -- & -- & $\begin{array}{c}1.0287 \\
(0.410)\end{array}$ & $\begin{array}{l}1.0150 \\
(0.220)\end{array}$ \\
\hline In a Serious Relationship & -- & -- & $\begin{array}{c}1.3864 \\
(1.310)\end{array}$ & $\begin{array}{c}1.4497 \\
(1.490)\end{array}$ \\
\hline $\begin{array}{l}\text { Observations } \\
\mathrm{R}^{2}\end{array}$ & $\begin{array}{c}813 \\
0.0784\end{array}$ & $\begin{array}{c}813 \\
0.1342\end{array}$ & $\begin{array}{c}813 \\
0.2056\end{array}$ & $\begin{array}{c}813 \\
0.1964\end{array}$ \\
\hline
\end{tabular}

